\title{
Paleointensities on 8 ka obsidian from Mayor Island, New Zealand
}

\author{
A. Ferk ${ }^{1,2}$, R. Leonhardt ${ }^{1}$, K.-U. Hess ${ }^{2}$, and D. B. Dingwell ${ }^{2}$ \\ ${ }^{1}$ Conrad Observatory, Central Institute for Meteorology and Geodynamics, 1190 Vienna, Austria \\ ${ }^{2}$ Department of Earth and Environmental Sciences, Ludwig-Maximilians-University, 80333 Munich, Germany
}

Received: 13 July 2011 - Published in Solid Earth Discuss.: 28 July 2011

Revised: 5 October 2011 - Accepted: 7 October 2011 - Published: 21 November 2011

\begin{abstract}
The $8 \mathrm{ka}$ BP (6050 BCE) pantelleritic obsidian flow on Mayor Island, Bay of Plenty, New Zealand, has been investigated using 30 samples from two sites. Due to a very high paramagnetic/ferromagnetic ratio, it was not possible to determine the remanence carriers. This is despite the fact that the samples were studied intensively at low, room, and high temperatures. We infer that a stable remanence within the samples is carried by single- or close to single-domain particles. Experiments to determine the anisotropy of thermoremanence tensor and the dependency on cooling rate were hampered due to alteration resulting from the repeated heating of the samples to temperatures just below the glass transition. Nonetheless, a well-defined mean paleointensity of $57.0 \pm 1.0 \mu \mathrm{T}$, based on individual high quality paleointensity determinations, was obtained. This field value compares very well to a paleointensity of $58.1 \pm 2.9 \mu \mathrm{T}$, which Tanaka et al. (2009) obtained for $5500 \mathrm{BCE}$ at a site $100 \mathrm{~km}$ distant. Agreement with geomagnetic field models, however, is poor. Thus, gathering more high-quality paleointensity data for the Pacific region and for the southern hemisphere in general to better constrain global field models is very important.
\end{abstract}

\section{Introduction}

The quality of global geomagnetic field models is always restricted by the quality and distribution of the included data. While the quality of paleodirections is assuredly high, paleointensities are thought to be less reliable. During the conduction of paleointensity experiments, one must be aware of potential problems such as alteration during geological time or even during the laboratory experiment itself (Valet et al., 1996), anisotropy of thermoremanence (Veitch et al., 1984),

Correspondence to: A. Ferk

(annika.ferk@geophysik.uni-muenchen.de)

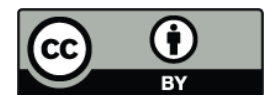

magnetic domain state bias (Leonhardt et al., 2004a), and different cooling histories in laboratory and nature (Fox and Aitken, 1980; Papusoi, 1972; Leonhardt et al., 2006). Especially during the last few years, several studies have tried to deal with these problems and to improve the quality of paleointensity determination either by introducing new methods (Dekkers and Böhnel, 2006; Fabian and Leonhardt, 2010; Muxworthy and Heslop, 2011) or by using samples that have remanence carriers in the SD range and for which corrections of some of the biasing effects are possible. Volcanic glass (Pick and Tauxe, 1993; Bowles et al., 2005; Leonhardt et al., 2006) and single silicate crystals with magnetic inclusions (Cottrell and Tarduno, 1999; Tarduno et al., 2007) have been proposed to be such ideal materials. Paleomagnetic data is by no means evenly distributed around the globe. Figure 1 shows the distribution of archeomagnetic and paleomagnetic data around the world for the last $10 \mathrm{ka}$ (Korte and Constable, 2005; Genevey et al., 2008). For example, the data set behind the global field model CALS7K by Korte and Constable (2005) consists mainly of data from Europe, Egypt, and Japan plus some data points from North America and Peru. For the rest of the world, especially for the southern hemisphere, data are very sparse. To address both of the problems noted above, i.e. quality and global distribution of data, an $8 \mathrm{ka}$ BP pantelleritic obsidian flow from Mayor Island, Bay of Plenty, New Zealand, has been analyzed. By studying pantelleritic volcanic glass, one should be able to rule out and/or correct for most biasing and other restricting effects. In this manner, high quality data would be obtained for a region in the southern Pacific for which, to date, very few paleomagnetic data exist. Unfortunately, alteration during the experiments hampered application of corrections for most samples. Nonetheless, high quality paleointensity data could be obtained as will be shown in the following sections

Published by Copernicus Publications on behalf of the European Geosciences Union. 

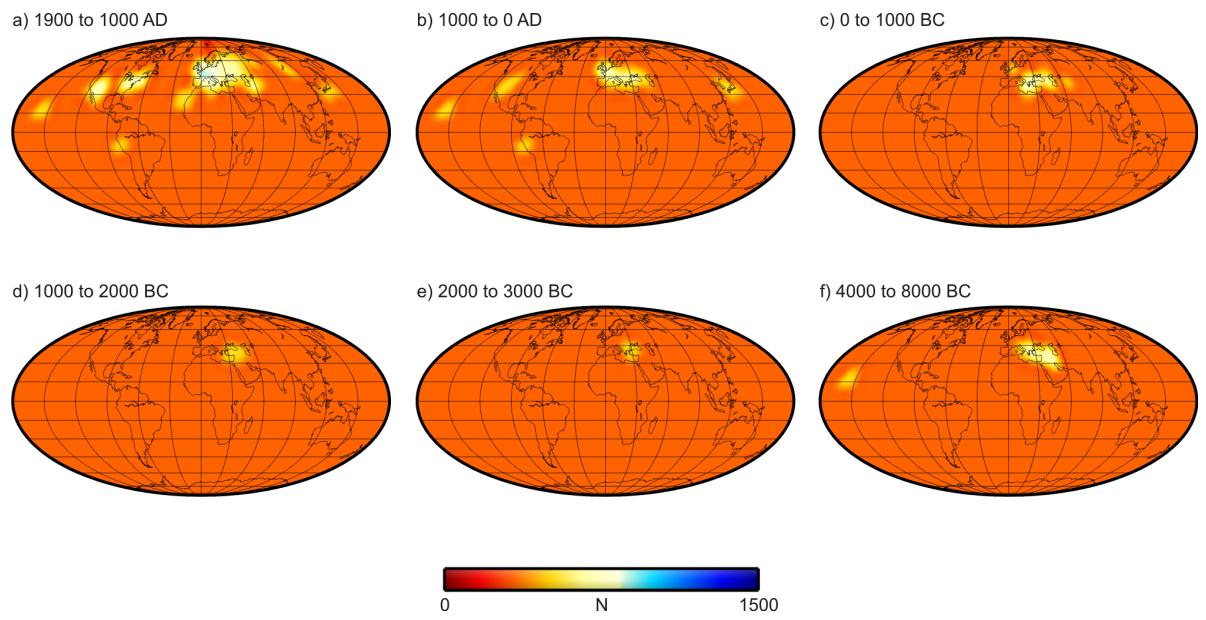

Fig. 1. Global distribution of archeomagnetic data from Korte and Constable (2005) and Genevey et al. (2008) for the last 10 ka.

\section{Geology and sampling}

Mayor Island (Tuhua) lies $26 \mathrm{~km}$ north of Tauranga, Bay of Plenty, New Zealand, in a back-arc setting $100 \mathrm{~km}$ behind the Taupo Volcanic Zone (Fig. 2). It is a volcano of Quaternary age (Houghton and Wilson, 1986) with rocks of peralkaline rhyolite composition that span the comenditepantellerite boundary of Macdonald's (1974) classification and are referred to as pantellerites by Stevenson et al. (1993). It rises $700 \mathrm{~m}$ from the sea floor from a base of a $15 \mathrm{~km}$ wide composite shield. The island is $4.5 \mathrm{~km}$ wide and dominated by a $3 \mathrm{~km}$ wide composite caldera whose steep walls rise 250 to $350 \mathrm{~m}$ above sea level. The caldera was built from three collapse events (Houghton et al., 1992), with the most recent one obscuring the form of the others. The $8000 \pm 70$ a BP $(6050 \pm 70$ BCE; radiocarbon-dated, Buck et al., 1981) flow studied in this paper predates this last collapse event (6.3 ka, Houghton and Wilson, 1986). The 8 ka deposit consists of a $1 \mathrm{~m}$ thick pumice fall bed that is overlain by a 20 to $70 \mathrm{~m}$ thick lava flow that drapes steeply over both the inner and outer walls of the caldera. Detailed petrographic and physical characteristics and the emplacement history of the flow can be found in Stevenson et al. (1993). The deposit is made up of finely vesicular pumice that forms a surface carapace and represents the upper $10 \mathrm{~m}$ of the flow. Below this follows an upper obsidian layer (UOBS) that gradually changes downwards to a central crystalline rhyolite layer. Beneath this rhyolite layer, a lower obsidian layer (LOBS) that incorporates a basal crumble layer is found above the already mentioned fall deposit (Stevenson et al., 1993). The deposit has been interpreted by Stevenson et al. (1993) as a fountain-fed flow that deformed after emplacement. All samples for this study were originally obtained by Gottsmann and Dingwell (2002) without orientation for their study on the thermal history of the 8 ka flow. A $70 \mathrm{~cm}$ thick vertical profile of LOBS (Fig. 6 in Gottsmann and Dingwell,
2002) was sampled at Hall's Pass, which is an area where the flow drapes back into the caldera. Sample names indicate sample number and vertical position measured from top, i.e. LOBS2.13: sample 2, at depth of $13 \mathrm{~cm}$. The sequence was taken above a crumble breccia containing disintegrated, sligthly fused pumices from the underlying pumice deposit and clasts of the overlying obsidian. Towards the central crystalline rhyolite on top of LOBS, a decimetre thick transition zone with obsidian fragments is incorporated into the rhyolite or in layers of folded glass and rock bands. In this transition zone gas blisters of $\sim 10 \mathrm{~cm}$ are found. At Parikoura Point on the east coast of the island, a horizontal profile was sampled through exposures of UOBS (Fig. 7 in Gottsmann and Dingwell, 2002). It consists of steeply inland dipping flow ridges and ramps. It was sampled at the northern cliff face along a slightly north-easterly inclined platform. The profile is $\sim 30 \mathrm{~m}$ long and comprises a sequence of anticlinal flow ridges and synclinal troughs between these ridges. Samples were taken from the exposed surfaces of the flow ridges. Sample names give horizontal profile distance in $\mathrm{cm}$, e.g. sample UOBS1420 is at $14.20 \mathrm{~m}$ in the profile. One flow ridge was sampled in a $5.2 \mathrm{~m}$ long detailed profile with spacing of 20 to $50 \mathrm{~cm}$ (samples UOBS700 to UOBS1220). In the transition zone from the central crystalline rhyolite to the UOBS, alternating bands of crystalline rhyolite and obsidian as well as an increase in bubble content are found. At the upper end of UOBS, gas blisters and increasing vesicularity show the transition to the finely vesicular pumice layer (Stevenson et al., 1993). Samples of both LOBS and UOBS are very pristine with no indication of secondary hydration or alteration processes. Both layers show very similar chemical composition with an average mol $\mathrm{Al}_{2} \mathrm{O}_{3} / \mathrm{mol}\left[\left(\mathrm{Na}_{2} \mathrm{O}+\mathrm{K}_{2} \mathrm{O}\right)\right]$ of 1.54 (Gottsmann and Dingwell, 2002), which does not change with layer depth or horizontal sample location within the sites (Gottsmann and Dingwell, 2002). 


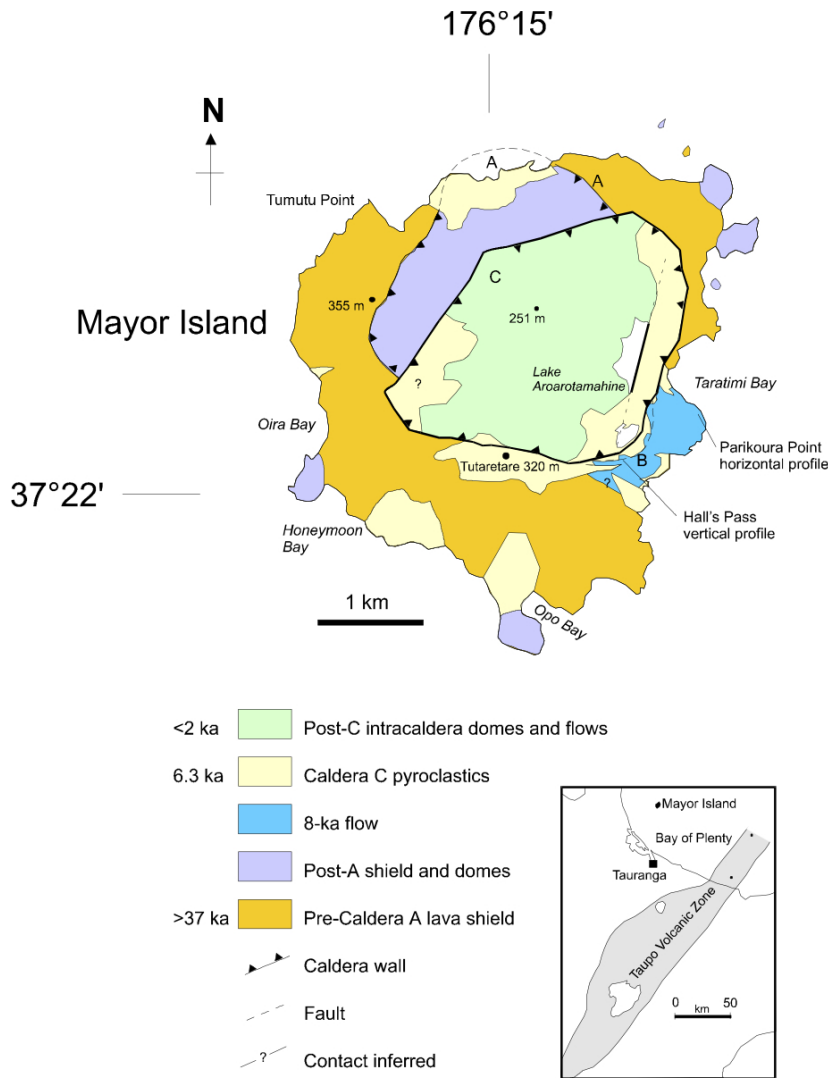

Fig. 2. Location of Mayor Island and geology map including the identification of caldera parts A, B, and C and location of investigated sites (LOBS: Hall's Pass, UOBS: Parikoura Point) within the 8 ka flow (blue). Taken from Gottsmann and Dingwell (2002).

\section{Relaxation geospeedometry}

Relaxation geospeedometry, i.e. measurements of the heat capacity at constant pressure $c_{\mathrm{p}}$, can be used to determine both the glass transition temperature $T_{\mathrm{g}}$ and the natural cooling rate. The theoretical and mathematical background for this method has been dicussed in detail by e.g. Wilding et al. (1995) and Gottsmann and Dingwell (2001). Here we only shortly introduce the general concept: By passing through the glass transition, the melt changes from liquid-like viscous to solid-like brittle behaviour (Dingwell and Webb, 1990); it goes from a thermodynamic state of metastable equilibrium to one of disequilibrium. Thus, $T_{\mathrm{g}}$ depends not only on the composition of the melt, but also on the quench rate. This information becomes frozen into the glass structure and can be gained by measurement of a structure-dependent physical property, such as heat capacity $c_{p}$, during reheating. Such relaxation geospeedometry had already been performed by Gottsmann and Dingwell (2002) on LOBS and UOBS samples. A detailed description of the experiments can be found there. Their measurements and modelling procedures resulted in modelled cooling rates
Table 1. Relaxation geospeedometry

\begin{tabular}{|c|c|c|}
\hline Sample & limiting $T_{\mathrm{f}}\left[{ }^{\circ} \mathrm{C}\right]$ & natural cooling rate $\left[\mathrm{K} \mathrm{min}^{-1}\right]$ \\
\hline LOBS 1.4 & 407 & 0.00072 \\
\hline LOBS2.13 & 409 & 0.00084 \\
\hline LOBS3.23 & 409 & 0.00114 \\
\hline LOBS4.33 & 412 & 0.0012 \\
\hline LOBS5.42 & 411 & 0.00114 \\
\hline LOBS6.53 & 420 & 0.0012 \\
\hline LOBS7.63 & 425 & 0.00174 \\
\hline LOBS8.73 & 454 & 0.01692 \\
\hline UOBSO & 429 & 0.00378 \\
\hline UOBS $120^{\mathrm{N}}$ & 489 & 6.3 \\
\hline UOBS $225^{\mathrm{N}}$ & 444 & 0.009 \\
\hline UOBS295 & 449 & 0.01122 \\
\hline UOBS700 & 411 & 0.0015 \\
\hline UOBS $720^{\mathrm{N}}$ & 425 & 0.0051 \\
\hline UOBS $750^{\mathrm{N}}$ & 454 & 0.00672 \\
\hline UOBS775 $\mathrm{N}$ & 450 & 0.00726 \\
\hline UOBS $837^{\mathrm{N}}$ & 447 & 0.00606 \\
\hline UOBS $889^{\mathrm{N}}$ & 452 & 0.00588 \\
\hline UOBS $925^{\mathrm{N}}$ & 412 & 0.00282 \\
\hline UOBS $986^{\mathrm{N}}$ & 420 & 0.00144 \\
\hline UOBS $1020^{\mathrm{N}}$ & 415 & 0.0012 \\
\hline UOBS $1080^{\mathrm{N}}$ & 405 & 0.00102 \\
\hline UOBS $1117^{\mathrm{N}}$ & 420 & 0.0012 \\
\hline UOBS $1153^{N}$ & 413 & 0.00114 \\
\hline UOBS 1220 & 453 & 0.0057 \\
\hline UOBS1420 & 417 & 0.00192 \\
\hline UOBS 1570 & 411 & 0.00174 \\
\hline UOBS $1705^{\mathrm{N}}$ & 432 & 0.0063 \\
\hline UOBS1825 & 418 & 0.00336 \\
\hline UOBS1945 & 444 & 0.0087 \\
\hline UOBS $2095^{\mathrm{N}}$ & 486 & 2.52 \\
\hline UOBS2245 & 419 & 0.00222 \\
\hline UOBS2380 & 430 & 0.00516 \\
\hline UOBS2650 & 448 & 0.01242 \\
\hline
\end{tabular}

Limiting fictive temperatures $T_{\mathrm{f}}$ and natural cooling rates of indicated samples. The limiting fictive temperature $T_{\mathrm{f}}$ is used to represent $T_{\mathrm{g}}$. It constitutes the temperature of the undercooled melt at which the glass structure is completely frozen in without any possibility for further structural relaxation, i.e. the lowest possible expression of $T_{\mathrm{g}}$.

ranging from $0.00072 \mathrm{~K} \mathrm{~min}^{-1}$ to $6.3 \mathrm{~K} \mathrm{~min}^{-1}$ and glass transition temperatures between $489{ }^{\circ} \mathrm{C}$ and $405{ }^{\circ} \mathrm{C}$ (Table 1). Within the vertical profile of LOBS, cooling rates increase from $0.00072 \mathrm{~K} \mathrm{~min}^{-1}$ close to the crystalline rhyolite to $0.017 \mathrm{~K} \mathrm{~min}^{-1}$ at the contact to the basal crumble breccia (Table 1). The centre of LOBS shows uniform cooling rates of $\sim 0.001 \mathrm{~K} \mathrm{~min}^{-1}$. Most of the samples of UOBS show cooling rates between $0.00102 \mathrm{~K} \mathrm{~min}^{-1}$ (UOBS1080, Table 1) and $0.01242 \mathrm{~K} \mathrm{~min}^{-1}$ (UOBS2650, Table 1). UOBS120 and UOBS2095 show much faster cooling rates of $6.3 \mathrm{~K} \mathrm{~min}^{-1}$ and $2.5 \mathrm{~K} \mathrm{~min}^{-1}$, respectively. 


\section{Magnetic mineralogy and domain state}

Rock magnetic measurements were performed to analyze magnetic mineralogy and domain state. Isothermal remanent magnetization (IRM) acquisition, isothermal backfield curves, hysteresis loops (all at room temperature), and thermomagnetic curves were measured on a Variable Field Translation Balance (VFTB) by Petersen Instruments at the University of Munich, Germany, using $8 \mathrm{~mm}$ diameter miniature cores. Further, hysteresis and backfield curves (at low, room, and high temperatures) were done on a lowtemperature (LT) Vibrating Sample Magnetometer (VSM) and on a high-temperature (HT) VSM (both by Princeton Measurements). For some samples, the temperature dependences of hysteresis and backfield were also measured on LTVSM and/or HTVSM. Additionally, thermomagnetic curves were measured with the HTVSM. Last but not least, the following experiments were done on a Magnetic Properties Measurement System (MPMS) by Quantum Design. For low temperature experiments in the MPMS, fields at room temperature (RT), at low temperature (LT, $10 \mathrm{~K}$ ), or during cooling of $2.5 \mathrm{~T}$ were applied and the field was turned off during the measurement: A RTSIRM (room temperature SIRM) was imparted on samples LOBS4.33, UOBS295, and UOBS1945 and measured during cooling to $10 \mathrm{~K}$, then a LTSIRM (low temperature SIRM) was imparted and measured during warming to RT. Sample UOBS1080 experienced a more detailed measurement procedure: After field-cooling (FC) to $10 \mathrm{~K}$, this FC remanence was measured during warming to RT. After another cooling in zero field to $10 \mathrm{~K}$, a LTSIRM was imparted and measured during warming to RT. Then a RTSIRM was imparted and measured during cooling to $10 \mathrm{~K}$ and during warming to RT. LTVSM, HTVSM, and MPMS experiments were done in the course of a visitor's fellowship at the Institute for Rock Magnetism at the University of Minneapolis, USA. Three LOBS $(1.4,4.33,8.73)$, and five UOBS $(120,295,925,1420,2095)$ samples were measured in the VFTB and the data were analyzed using the RockMagAnalyzer software by Leonhardt (2006). All three LOBS samples are mainly paramagnetic, but have a remanent content that is high enough to get good IRM and backfield curves (Fig. 3a i). For samples LOBS1.4 and 8.73, it is also possible to determine a Curie temperature $T_{\mathrm{C}}$ of $\sim 210{ }^{\circ} \mathrm{C}$ (Fig. 3a iii) even though the departure of the thermomagnetic curves from a curve calculated for the decrease in saturation magnetisation of paramagnetic particles (green line in Fig. 3a iii) is not very strong. For $T_{\mathrm{C}}$ determination, this paramagnetic decrease was subtracted from the original thermomagnetic curve. Later remanence measurements (section 5) show unblocking of grains in LOBS8.73 up to at least $400{ }^{\circ} \mathrm{C}$. This implies a contribution from remanence carriers that do not show in the thermomagnetic curves due to the high paramagnetic contribution. LOBS1.4 plots in and LOBS8.73 close to the single domain (SD) region of the Day plot (Day et al., 1977). The hysteresis loop of sample LOBS4.33 is dominated by paramagnetic behaviour and thus, no meaningful hysteresis parameters can be obtained. Samples from UOBS are even more paramagnetic than LOBS4.33. Hysteresis measurements show only a sligthly broadened straight line through the origin (Fig. 3b ii) and IRM and backfield measurements are very noisy even though a remanent contribution can clearly be seen (Fig. 3b i). For thermomagnetic curves, deviations from the paramagnetic decrease are so small that no Curie temperatures can be determined (Fig. 3b iii). As the very strong paramagnetic contribution mostly prevented obtaining meaningful data using the VFTB, further measurements were done on the more sensitive MPMS and VSMs. However, their higher sensitivity could not totally make up for the smaller sample sizes and so again mainly the strong paramagnetic contribution was monitored: Hysteresis and backfield data at room temperature (RT) were taken for every sample. Hysteresis plots are almost always dominated by the paramagnetic contribution (e.g. UOBS 1080 in Fig. 4a i). A small ferrimagnetic contribution can be seen when the loops are corrected for the high field slope (Fig. 4a ii), but the measurement noise is much too high to determine hysteresis parameters. Only sample UOBS1945 (Fig. 4b i) shows a stronger hysteresis, but is again too much dominated by paramagnetism to determine $H_{\mathrm{c}}$ (Fig. 4b ii). Further, it was impossible to determine $H_{\mathrm{cr}}$ values from the backfield curves as there is always some shift in the data: Fig. 4a iii shows that at the end of the measurement, not the same absolute value in magnetization as before was obtained. For some samples the y-axis was not even crossed. It was not possible to find any reason for this shift and hence, no correction could be applied. For samples LOBS4.33, UOBS295, and UOBS1945, hysteresis and for UOBS1080 hysteresis and backfield curves were also measured in $10^{\circ} \mathrm{C}$ steps from $10 \mathrm{~K}$ to room temperature and in $25^{\circ} \mathrm{C}$ steps from room temperature to $\sim 450^{\circ} \mathrm{C}$. However, no further insights regarding the remanence carriers could be gained from these measurements as the paramagnetic contribution stayed dominant during the hysteresis loops, and backfield measurements were as erroneous as those at room temperature. Thermomagnetic curves for LOBS7.63 and UOBS700 are also similar to those of the VFTB; they only show slight deviations from paramagnetic decay. For UOBS700 a little kink below $\sim 400{ }^{\circ} \mathrm{C}$ implies a Curie temperature in this range, but the data is not very clear. MPMS data of LOBS4.33, UOBS295, UOBS1945, and UOBS1080 can be found in Fig. 5a, b, c and d, respectively. Neither at $\sim 262 \mathrm{~K}$ (Hematite Morin transition) nor at $\sim 120 \mathrm{~K}$ (Magnetite Verwey Transition) are any remarkable changes in the different remanent magnetizations observed. However, there is always a strong decrease in RTSIRM during cooling and a respective increase in LTSIRM below $50-75 \mathrm{~K}$. This is most probably connected to the high paramagnetic/ferro(i)magnetic ratio: Within the MPMS the field is not perfectly zeroed. There seems to be a small negative residual field of $\pm 1-2 \mu \mathrm{T}$. Paramagnetic susceptibility is inversely proportional to temperature and, thus, 
at low temperatures an induced negative magnetization partially cancels out the positive remanence. Sample UOBS295 (Fig. 5b) shows a more sharp decrease in RTSIRM during cooling which hints to ordering or a phase transition rather than to gradual increase in paramagnetic susceptibility. However, the LTSIRM warming curve does not show a sudden increase and an interpretation is therefore difficult. All warming curves show decreases above 50-75 K. Such decreases may have different reasons like unblocking of superparamagnetic (SP) grains or domain reorganization in MD high-Ti titanomagnetite (Moskowitz et al., 1998). However, for our samples VFTB experiments have shown that we are dealing with SD or close to SD remanence carriers. Hence, the second possibility can be ruled out and instead it is followed that nanoparticles go from SP to stable SD. The difference between FC remanence and LTSIRM warming curves in Fig. 5d may be explained with a phase of extremly high coercivity, which is either due to the presence of an imperfect antiferromagnetic phase with a low ordering temperature (50-100 K) that is magnetized more efficiently by field-cooling (strongfield TRM) than isothermally at $10 \mathrm{~K}$ or with the presence of low temperature partially oxidized nano-(titano-)magnetites. An identification of remanence carriers is not possible based on the so far performed VFTB, VSM, and MPMS experiments. The strong paramagnetic contribution constrains analysis of the ferro(i)magnetic particles. However, the small grain sizes and the small but clearly existing remanence suggest that paleointensity determination is worth a try.

\section{Paleointensity determination}

\subsection{Thellier-type experiments}

Paleointensity experiments on $8 \mathrm{~mm}$ diameter miniature cores and on 1-in cores were done in a MMTD20 thermal demagnetizer in the paleomagnetic laboratory of the University of Munich, Germany, in Niederlippach and in a MMTD60 thermal demangetizer in the laboratory of the Montan University Leoben, Austria, in Gams. For infield steps, laboratory fields of $30 \pm 0.1 \mu \mathrm{T}$ were applied during heating and cooling. The experiments followed the modified Thellier-technique MT4 by Leonhardt et al. (2004b), which is a zero-field first method that incorporates pTRM checks (Coe, 1967), additivity checks (Krása et al., 2003), and pTRM tail checks (Riisager and Riisager, 2001). Directional differences between the applied field and the NRM of the pTRM-tail check are taken into account according to Leonhardt et al. (2004a). All determinations were analyzed using the ThellierTool4.21 software (Leonhardt et al., 2004b). Paleointensity data are summarized in Table 2 with sample subscripts $\mathrm{m}$, NL and G denoting minicores, Niederlippach and Gams, respectively, and different Arai plots are given in Fig. 6. Measurements in Nieder-
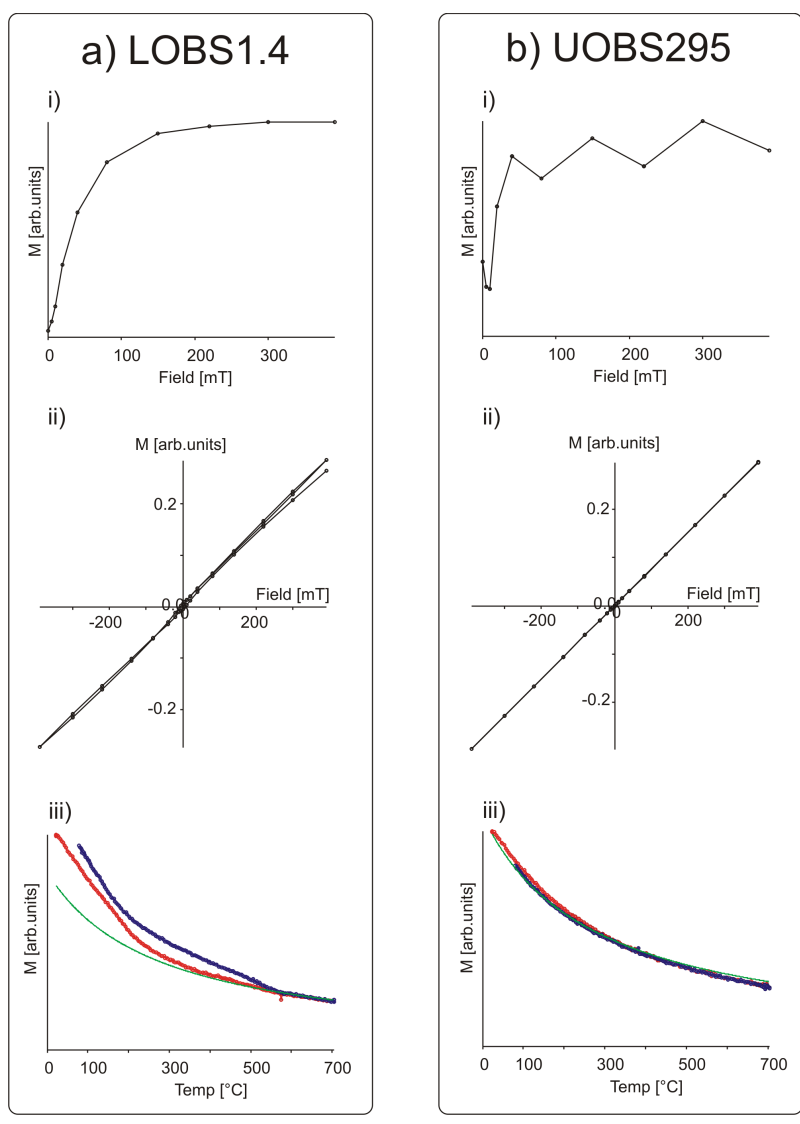

Fig. 3. VFTB measurements for samples (a) LOBS1.4 and (b) UOBS295: (i) IRM acquisition, (ii) hysteresis loops, and (iii) thermomagnetic curves (red: heating, blue: cooling, green: paramagnetic decay).

lippach proceeded to temperatures above $T_{\mathrm{g}}$ even though $\mathrm{NRM}_{\text {left }}$ had already been only $\sim 10 \%$ at $\sim 390{ }^{\circ} \mathrm{C}$. Alteration of these samples gets very strong above $T_{\mathrm{g}}$, leading to departing checks (e.g. Fig. 6a). As this alteration is most likely connected to relaxation of the glass structure, only steps below $T_{\mathrm{g}}$ are considered for paleointensity determination, i.e. only steps up to $390{ }^{\circ} \mathrm{C}$ (7 steps), while higher temperature steps are disregarded. This accounts for the two miniature samples LOBS8.73 and UOBS2095 as well as for the 81 -in cores measured in Niederlippach (subscript NL in Table 2). With this experience in mind, 24 samples (inch cores) in the Gams laboratory were heated up to $390{ }^{\circ} \mathrm{C}$ in 10 steps. Almost all samples were then demagnetized to at least $15 \%$. Only samples UOBS889 (Fig. 6d), 1570, and 2380 had $\sim 20 \%$, UOBS0 $\sim 40 \%$ and UOBS1945 and 2095 $\sim 50 \%$ left. Paleointensity determinations are of good quality. In total, data from 24 of the 34 measured samples (70\%) could be used with good values for different quality parameters: Mostly fraction of the NRM $\mathrm{f}$ (Coe et al., 1978) and gap factor $\mathrm{g}$ (Coe et al., 1978) are greater than 0.7; quality factor q (Coe et al., 1978) ranges between 7.5 and 100, though 

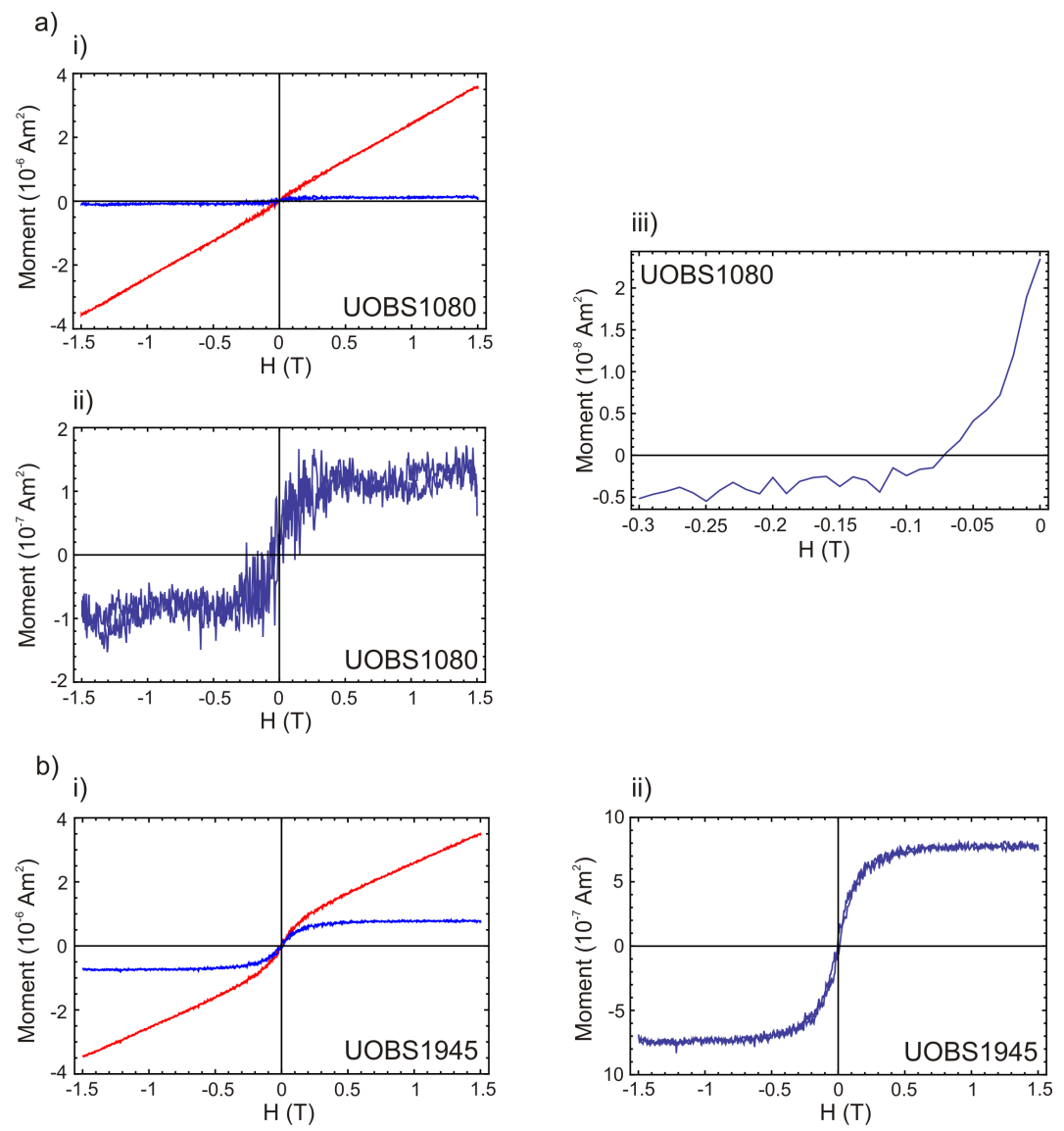

Fig. 4. VSM measurements at $50{ }^{\circ} \mathrm{C}$ for (a) UOBS1080 and (b) UOBS1945. Graphs show (i) hysteresis loops as measured (red) and corrected for the high field slope ( $>1 \mathrm{~T}$, blue) and (ii) the corrected loops seperately in blow-ups. (iii) gives an additional backfield curve for UOBS 1080 .

mostly between 15 and 30 . In many of the experiments, an onset of alteration is observed at temperature steps above $\sim 300^{\circ} \mathrm{C}$, which is probably related to the repeated heating to temperatures close to $T_{\mathrm{g}}$. However, for the temperature intervals used for paleointensity determination, the difference ratio DRAT (Selkin and Tauxe, 2000), which measures deviations in pTRM checks, is typically $\leq 5.1$, suggesting the data are reliable. Repeated thermal demagnetizations (one before and one after the pTRM acquisition of the respective temperature step) show only minor deviations $(\mathrm{d}(\mathrm{TR}) \leq 2.1 \%$, d(TR): Leonhardt et al. (2004b)) indicative of SD remanence carriers for $63 \%$ of the samples and slightly higher values (up to $\mathrm{d}(\mathrm{TR})=5.5 \%$ ) indicative of small PSD particles for the others, although an unique interpretation in terms of domain size is hampered by the above mentioned alterations above $\sim 300{ }^{\circ} \mathrm{C}$ before the remanence is unblocked. Arithmetic means and standard deviations for LOBS and UOBS are $56.5 \pm 2.0 \mu \mathrm{T}$ and $59.2 \pm 8.4 \mu \mathrm{T}$, respectively. For the whole 8 ka flow, a weighted mean (using 1/(arithmetic standard deviation) as weighting factor) of $57.0 \pm 1.0 \mu \mathrm{T}$ is calculated.

\subsection{Anisotropy correction}

As samples in Niederlippach had been heated too high, no anisotropy or cooling rate experiments (Subsection 5.3) could be performed on these samples. Relaxation at the glass transition altered the samples and no meaningful results can be obtained. However, for Gams samples these experiments could be carried out. If a rock is magnetically anisotropic, this means that its ability to acquire a magnetization in a magnetic field depends on its orientation with respect to that field. The anisotropy tensor of TRM (ATRM tensor) can be obtained as weak field TRM is proportional to the field strength. Determinations of the ATRM tensor were done on the same samples as paleointensity determinations in the MMTD60 demagnetizer in the Gams laboratory. TRMs were imparted using in-field heating/cooling cycles to the upper end of the blocking spectra of the samples, i.e. up to $390{ }^{\circ} \mathrm{C}$, subsequently in $+\mathrm{z},+\mathrm{x},-\mathrm{x},+\mathrm{y}$, $-\mathrm{y}$ and $-\mathrm{z}$ direction. Additionally, the $+\mathrm{z}$ treatment was repeated in the end to check for alteration. The measurements were analyzed following the approach of Veitch et 
a)

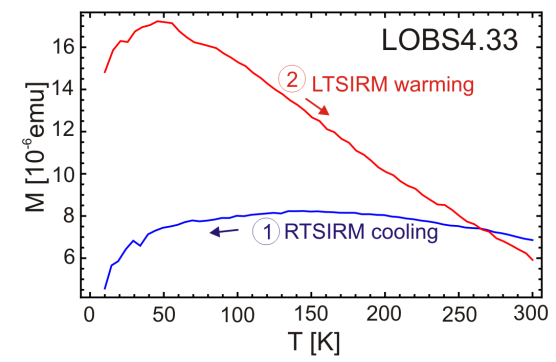

c)

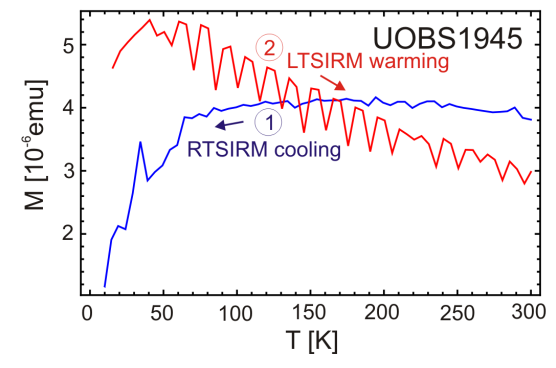

b)

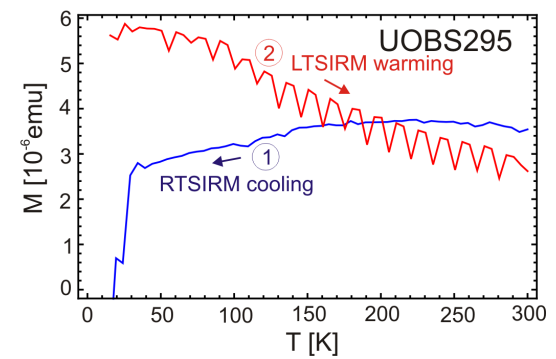

d)

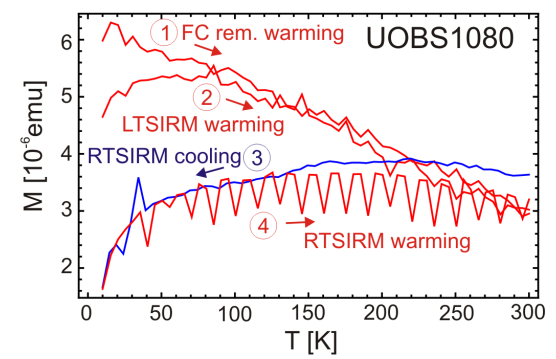

Fig. 5. MPMS measurements for samples (a) LOBS4.33, (b) UOBS295, (c) UOBS1945, and (d) UOBS1080. (a), (b), and (c) show 1. a room temperature (RT) SIRM measured during cooling and 2. a low temperature (LT, at $10 \mathrm{~K}$ ) SIRM measured during warming. (d) shows 1. a field cooled remanence measured during warming, 2. a LTSIRM measured during warming, 3. a RTSIRM measured during cooling, and 4. during warming. In all cases measurements were done in zero field and applied fields for RTSIRM, LTSIRM and field cooling were 2.5 T.

a)

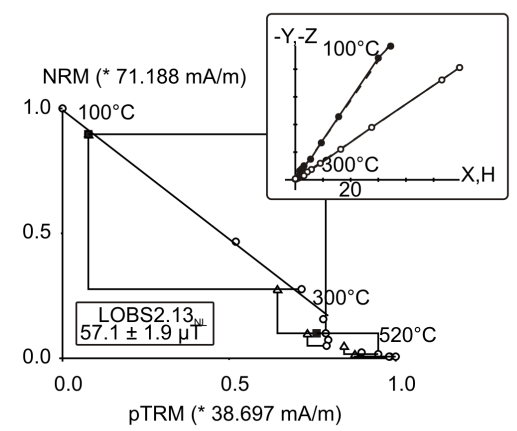

c)

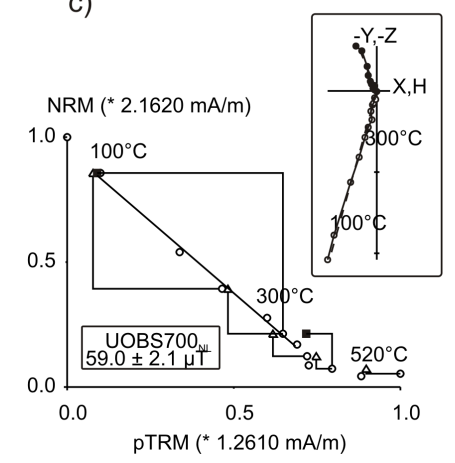

b)

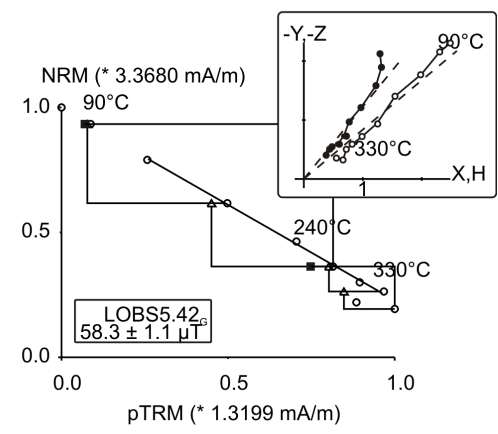

d)

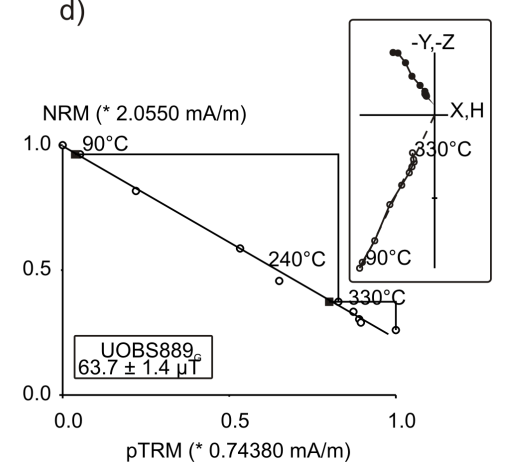

Fig. 6. NRM/pTRM plots and respective orthogonal projections for (a) LOBS2.13, (b) LOBS5.42, (c) UOBS700 and (d) UOBS889. Triangles and squares in the NRM/pTRM plots indicate pTRM checks (CK) and additivity checks (AC), respectively. 
Table 2. Paleointensity results and correction.

\begin{tabular}{|c|c|c|c|c|c|c|c|c|c|c|}
\hline \multirow{2}{*}{ Sample } & \multirow{2}{*}{$\begin{array}{c}\text { Uncorr. paleointensity } \\
H_{\mathrm{UC}}[\mu T]\end{array}$} & \multicolumn{5}{|c|}{ quality parameters } & \multicolumn{2}{|c|}{ ATRM correction } & \multicolumn{2}{|c|}{ CR correction } \\
\hline & & $f$ & $g$ & $q$ & DRAT & $\mathrm{d}(\mathrm{TR})$ & $f_{\mathrm{ATRM}}$ & $H_{\mathrm{ATRM}}[\mu T]$ & $f_{\mathrm{CR}}$ & $H_{\mathrm{ATRM}, \mathrm{CR}}[\mu T]$ \\
\hline LOBS & $56.5 \pm 2.0$ & & & & & & & & & \\
\hline $\begin{array}{l}\text { LOBS } 2.13_{\mathrm{NL}} \\
\text { LOBS } 3.23_{\mathrm{G}}\end{array}$ & $57.1 \pm 1.9$ & 0.83 & 0.63 & 15.5 & 4.2 & 2.9 & & & & \\
\hline LOBS $4.33_{\mathrm{NL}}$ & $55.5 \pm 1.2$ & 0.83 & 0.81 & 32.5 & 1.9 & 2.9 & & & & \\
\hline LOBS $5.42_{\mathrm{G}}$ & $58.3 \pm 1.1$ & 0.54 & 0.75 & 21.1 & 3.0 & 2.1 & $(1.244 \pm 0.218)$ & $(72.5 \pm 14.1)$ & & \\
\hline LOBS6.53 $3_{\mathrm{G}}$ & & & & & & & & & & \\
\hline LOBS6.53NL & $58.9 \pm 4.2$ & 0.74 & 0.73 & 7.5 & 4.4 & 3.7 & & & & \\
\hline LOBS7.63 ${ }_{\mathrm{G}}$ & $53.5 \pm 0.9$ & 0.69 & 0.72 & 28.5 & 2.3 & 0.9 & & & & \\
\hline LOBS $8.73_{\mathrm{m}}$ & & & & & & & & & & \\
\hline LOBS8.73 NL & $56.0 \pm 1.9$ & 0.75 & 0.64 & 14.5 & 8.1 & 5.0 & & & & \\
\hline UOBS & $59.2 \pm 8.4$ & & & & & & & $61.1 \pm 8.9$ & & \\
\hline $\mathrm{UOBSO}_{\mathrm{G}}$ & & & & & & & & & & \\
\hline UOBS $120_{\mathrm{G}}$ & $65.2 \pm 2.0$ & 0.67 & 0.78 & 17.3 & 2.8 & 1.4 & & & & \\
\hline $\mathrm{UOBS}_{225_{\mathrm{G}}}$ & $68.7 \pm 2.9$ & 0.85 & 0.83 & 16.6 & 2.0 & 2.5 & & & & \\
\hline${\text { UOBS } 295_{\mathrm{G}}}^{-}$ & $73.9 \pm 2.9$ & 0.85 & 0.82 & 17.7 & 4.1 & 2.0 & & & & \\
\hline $\mathrm{UOBS} 700_{\mathrm{G}}$ & $42.3 \pm 0.4$ & 0.69 & 0.73 & 60.1 & 3.4 & 0.4 & & & & \\
\hline $\begin{array}{l}\mathrm{UOBS} 700_{\mathrm{NL}} \\
\mathrm{UOBS} 71_{\mathrm{G}}\end{array}$ & $59.0 \pm 2.1$ & 0.72 & 0.72 & 14.2 & 1.6 & 1.8 & & & & \\
\hline UOBS $720_{\mathrm{G}}$ & $46.9 \pm 2.5$ & 0.76 & 0.75 & 10.6 & 2.5 & 3.4 & $(1.190 \pm 1.950)$ & $(55.8 \pm 94.4)$ & & \\
\hline UOBS750 & $72.5 \pm 3.2$ & 0.79 & 0.74 & 13.3 & 3.5 & 2.1 & & & & \\
\hline $\mathrm{UOBS}_{775_{\mathrm{G}}}$ & $56.6 \pm 0.4$ & 0.93 & 0.77 & 100.2 & 1.6 & 1.4 & $(1.051 \pm 0.278)$ & $(59.5 \pm 16.2)$ & & \\
\hline UOBS837 $\mathrm{NL}$ & & & & & & & & & & \\
\hline UOBS $889_{\mathrm{G}}$ & $63.7 \pm 1.4$ & 0.76 & 0.82 & 27.3 & 0.0 & 1.2 & $1.113 \pm 0.037$ & $70.9 \pm 3.9$ & $1.106 \pm 0.074$ & $64.1 \pm 0.7$ \\
\hline UOBS $925_{\mathrm{NL}}^{\mathrm{U}}$ & $54.6 \pm 2.4$ & 0.82 & 0.68 & 12.5 & 1.1 & 3.9 & & & & \\
\hline UOBS $1020_{\mathrm{G}}$ & $58.0 \pm 2.7$ & 0.97 & 0.77 & 15.9 & 6.2 & 5.5 & & & & \\
\hline $\begin{array}{l}\mathrm{UOBS} 1080_{\mathrm{NL}} \\
\mathrm{UOBS} 1117_{\mathrm{G}}\end{array}$ & $64.1 \pm 2.3$ & 0.95 & 0.61 & 16.3 & 3.5 & 3.7 & & & & \\
\hline UOBS $1420_{\mathrm{G}}$ & & & & & & & & & & \\
\hline UOBS $1570_{\mathrm{G}}$ & $56.3 \pm 1.4$ & 0.75 & 0.78 & 24.4 & 1.4 & 1.8 & $1.238 \pm 0.013$ & $69.7 \pm 2.4$ & & \\
\hline UOBS $1705_{\mathrm{G}}$ & $53.1 \pm 1.7$ & 0.88 & 0.81 & 22.6 & 2.8 & 0.6 & $(1.067 \pm 0.119)$ & $(56.6 \pm 8.1)$ & & \\
\hline UOBS $1825_{\mathrm{G}}$ & & & & & & & & & & \\
\hline UOBS $1945_{\mathrm{G}}$ & $62.7 \pm 2.0$ & 0.44 & 0.84 & 11.6 & 5.1 & 0.6 & $(0.929 \pm 0.239)$ & $(58.2 \pm 16.8)$ & & \\
\hline UOBS2095m & & & & & & & & & & \\
\hline $\mathrm{UOBS}^{2} 2095_{\mathrm{G}}$ & $50.1 \pm 1.9$ & 0.39 & 0.80 & 8.1 & 4.3 & 0.9 & $1.159 \pm 0.050$ & $58.0 \pm 4.7$ & & \\
\hline UOBS $2245_{\mathrm{G}}$ & $62.3 \pm 2.6$ & 0.84 & 0.78 & 15.9 & 3.5 & 0.7 & & & & \\
\hline $\mathrm{UOBS}^{2} 380_{\mathrm{G}}$ & $55.2 \pm 1.9$ & 0.63 & 0.78 & 14.5 & 2.7 & 0.9 & & & & \\
\hline 8 ka flow & $57.0 \pm 1.0$ & & & & & & & $59.3 \pm 2.2$ & & \\
\hline
\end{tabular}

$H_{\mathrm{UC}}, H_{\mathrm{ATRM}}$ and $H_{\mathrm{ATRM}, \mathrm{CR}}$ are the paleointensity values of the individual samples with associated errors for the uncorrected, ATRM corrected and ATRM and cooling rate (CR) corrected determinations, respectively. $H_{\mathrm{ATRM}}$ errors are calculated as minimum-maximum errors including the uncertainty of the uncorrected paleointensity $\sigma_{\mathrm{UC}}$ and of the ATRM correction factor $f_{\mathrm{ATRM}}$. $H_{\mathrm{ATRM}}$ CR errors are calculated via full error propagation using the uncertainties of $H_{\mathrm{UC}}, f_{\mathrm{ATRM}}$ and $f_{\mathrm{CR}}$. Also shown are arithmetic means and standard deviations of the different sites and weighted means for the whole 8 ka flow (using $1 /$ (arithmetic standard deviation of site means) as weighting parameter). Additionally, the following quality parameters for the individual paleointensity determinations are given: fraction of NRM $f$ (Coe et al., 1978), gap factor $g$ (Coe et al., 1978), quality factor $q$ (Coe et al., 1978), difference ratio DRAT (Selkin and Tauxe, 2000) and d(TR) (Leonhardt et al., 2004b).

al. (1984) and the results are summarized in Table 2. After determining the ATRM tensor, a paleointensity scaling factor, $f_{\mathrm{ATRM}}\left(H_{\mathrm{ATRM}}=H_{\mathrm{UC}} \times f_{\mathrm{ATRM}}(\mathrm{UC}\right.$ : uncorrected $\left.)\right)$, is calculated based on the directions of the ancient field and the laboratory field. $f_{\text {ATRM }}$ is not only determined from the averaged axes components but also separately for positive $(+\mathrm{x},+\mathrm{y},+\mathrm{z})$ and negative $(-\mathrm{x},-\mathrm{y},-\mathrm{z})$ measurements, i.e. $f_{\mathrm{ATRM}}^{\mathrm{pos}}$ and $f_{\mathrm{ATRM}}^{\text {neg }}$. The uncertainty of $f_{\mathrm{ATRM}}$ is calculated by $\sigma\left(f_{\text {ATRM }}\right)=\left(\left|f_{\text {ATRM }}^{\text {pos }}-f_{\text {ATRM }}^{\text {neg }}\right|\right.$. The uncertainty $\sigma\left(H_{\text {ATRM }}\right)$ of the ATRM corrected paleointensity is a minimium-maximum error including the uncertainty of the uncorrected paleointensity $\sigma\left(H_{\mathrm{UC}}\right)$ and of the correction factor $\sigma\left(f_{\text {ATRM }}\right)$. For only 8 of the 24 samples was alteration small enough to correct for anisotropy. Fig. 7 shows that in most cases the two $+\mathrm{z}$ measurements at the beginning and at the end of the experiment varied by $\geq 5 \%$. Therefore, anisotropy correction was tried only for samples LOBS5.42, UOBS720, 775, 889, 1570, 1705, 1945 and 2095. As mentioned above, samples UOBS889, 1570, 1945 and 2095 still have $\mathrm{NRM}_{\text {left }}>15 \%$ at $390{ }^{\circ} \mathrm{C}$. As their $T_{\mathrm{g}}$ is in the same range as the one of the other samples, it was decided to stop heating them further and to determine the ATRM tensor at 

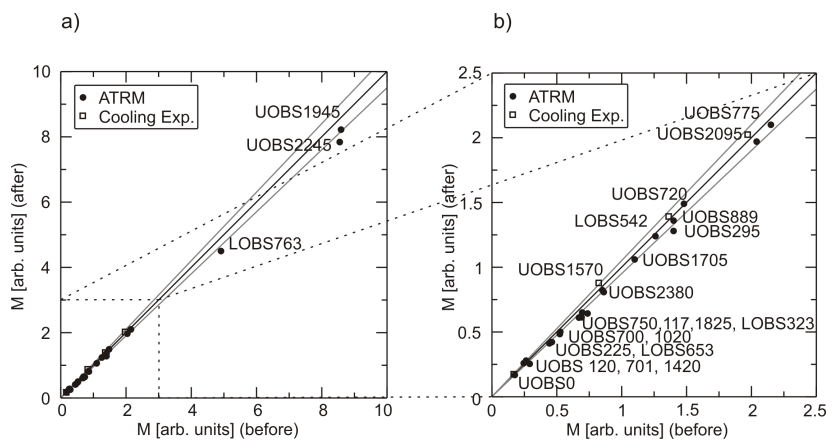

Fig. 7. Comparison of magnetization before and after the ATRM (filled circle) and cooling rate (open square) experiments. Diagonal in the plots represents no alteration and grey cone around this line gives $5 \%$ deviation between the two measurements. (b) shows close-up of lower left corner of (a).

$390{ }^{\circ} \mathrm{C}$. Vector subtraction of the TRM remaining at $390{ }^{\circ} \mathrm{C}$ from each step in the anisotropy experiment should yield a reasonable measure of the ATRM tensor. Although TRM capacity remained stable, as has been shown by the $\leq 5 \%$ difference between the two $+\mathrm{z}$ measurements, very high relative errors $\sigma\left(f_{\text {ATRM }}\right) / f_{\text {ATRM }}$ of $11-164 \%$ were found for most samples (data for $f_{\text {ATRM }}$ and $H_{\text {ATRM }}$ in brackets in Table 2). These high errors suggest that there was alteration during these experiments that was not monitored by the two $+\mathrm{z}$ measurements. Either alteration did not affect the tensor in this direction or it was just by chance that these two measurements showed similar values. Only samples UOBS889, 1570 and 2095 showed relative errors $<5 \%$, which were thought to represent reliable measurements. Thus, for the anisotropy corrected paleointensity values of $61.1 \pm 8.9 \mu \mathrm{T}$ for UOBS and $59.3 \pm 2.2 \mu \mathrm{T}$ for the whole flow only corrected paleointensities of these three samples, and uncorrected paleointensities of all other samples were used. In both cases the paleointensity is slightly increased but within error identical to the uncorrected mean values.

\subsection{Corrections for cooling rate dependence}

In the 1980s, several studies (Halgedahl et al., 1980; Dodson and McClelland-Brown, 1980; Fox and Aitken, 1980; McClelland-Brown, 1984) have shown that non-interacting SD particles acquire a smaller TRM during faster cooling. How exactly the TRM depends on cooling rate varies, however, with slight changes in grain size and domain state. Hence, to correct overestimation of paleointensity (Leonhardt et al., 2006; Ferk at al., 2010), the TRM dependency on cooling rate as well as natural cooling rates (via relaxation geospeedometry) have to be determined. For these measurements the same samples as for Thellier-Thellier and anisotropy experiments are subjected to magnetic cooling rate dependency investigations in the MMTD60 using two laboratory cooling rates (Leonhardt et al., 2006). As most of our samples had altered already during the anisotropy experiments, only samples UOBS889, 1570 and 2095 that did not show remarkable alteration were subjected to cooling rate experiments. For fast cooling the cooling fan of the furnace was used like during the previous experiments, while for slow cooling the samples were cooled without fan operation. Laboratory cooling rates were determined on basaltic dummy samples across the glass transition intervals of our samples, i.e. between about $500{ }^{\circ} \mathrm{C}$ and $400{ }^{\circ} \mathrm{C}$. A conservative estimate of the uncertainty in cooling rate determination is $10 \%$ for fast cooling and $5 \%$ for slow cooling. First, a fast heating/cooling cycle with a cooling rate of $\approx 55.6 \mathrm{~K} \mathrm{~min}^{-1}$ was used to induce a TRM $\left(\mathrm{TRM}_{\mathrm{f}, 1}\right)$. Then a heating/cooling cycle with a ca. 43-fold slower cooling rate of $\approx 1.3 \mathrm{~K} \mathrm{~min}^{-1}\left(\mathrm{TRM}_{\mathrm{s}, 1}\right)$ and finally, another fast cycle $\left(\mathrm{TRM}_{\mathrm{f}, 2}\right)$ in order to check for alterations during the experiment, were performed. $\mathrm{TRM}_{\mathrm{f}, 1}$ and $\mathrm{TRM}_{\mathrm{f}, 2}$ of UOBS1570 differ by $7 \%$, indicating strong alterations (Fig. 7b). For UOBS2095, TRM $\mathrm{f}_{\mathrm{f}, 1}$ and $\mathrm{TRM}_{\mathrm{f}, 2}$ are within $3 \%$, but $\mathrm{TRM}_{\mathrm{f}, 2}>\mathrm{TRM}_{\mathrm{s}, 1}$ which makes a cooling-rate correction impossible. A reliable result was obtained only for UOBS889: $\mathrm{TRM}_{\mathrm{f}, 1}$ and $\mathrm{TRM}_{\mathrm{f}, 2}$ differ only by $2 \%$, indicating only very minor alteration. This difference between $\mathrm{TRM}_{\mathrm{f}, 1}$ and $\mathrm{TRM}_{\mathrm{f}, 2}$ is used as an error estimate for $\mathrm{TRM}_{\mathrm{s}, 1}$ and $\mathrm{TRM}_{\mathrm{f}, 1}$. The TRM intensity for slow cooling is $6 \%$ larger than for fast cooling, as would be expected for noninteracting SD particles (Halgedahl et al., 1980; Dodson and McClelland-Brown, 1980). Linear extrapolation of the magnetic cooling-rate dependency to the natural cooling rate, as determined by relaxation geospeedometry, is performed in order to correct the overestimation of $H_{\text {ATRM }}$. Such linear extrapolation is valid if the remanence carriers are noninteracting SD particles that dominantly block close to the respective blocking temperature (Halgedahl et al., 1980). As has been mentioned before, it was not possible to determine unambigiously the domain size of most LOBS and UOBS samples, as mostly rock magnetic measurements were not sensitive enough. However, both successful rock magnetic experiments for LOBS1.4 and 8.73 and thermal demagnetization steps (thermal repeat: TR) after imparting the pTRM during paleointensity determinations, i.e. the tail checks, imply SD or small PSD remanence carriers. Also, TR steps of UOBS 889 differ only by $1.2 \%$, suggesting SD particles. However, unblocking of the TRM occurs mainly over a temperature range of $200^{\circ} \mathrm{C}$. Thus, the second requirement is not strictly fulfilled. Nevertheless, as there is no other theory regarding cooling rate dependency for such samples, linear extrapolation was used as an approximation of cooling rate dependency. The previous error estimates for inaccuracy of laboratory cooling rate and magnetization determination allow a minimum-maximum error propagation towards the natural cooling rates. The obtained cooling rate correction factor $f_{\mathrm{CR}}=\mathrm{TRM} / \mathrm{TRM}_{\mathrm{f}, 1}$ is then used to correct the paleointensity values $H_{\mathrm{ATRM}}$ by $H_{\mathrm{ATRM}, \mathrm{CR}}=H_{\mathrm{ATRM}} / f_{\mathrm{CR}}$. Full error propagation, including the uncertainties of the paleointensity 
experiments as well as those of $f_{\mathrm{ATRM}}$ and $f_{\mathrm{CR}}$, gives the uncertainty $\sigma\left(H_{\mathrm{ATRM}, \mathrm{CR}}\right)$ of $H_{\mathrm{ATRM}, \mathrm{CR}}$. The resulting paleointensity, $64.1 \pm 0.7 \mu \mathrm{T}$ for UOBS889, is practically identical to its uncorrected value of $63.7 \pm 1.4 \mu \mathrm{T}$. Both are slightly higher than the mean values for the whole 8 ka flow.

\section{Discussion}

Even though many rockmagnetic experiments at low, room, and high tempertures were performed, it was not possible to determine the remanence carriers due to the very high paramagnetic contribution. However, it was found that the samples carry a small but stable remanence that is carried by SD or close to SD remanence carriers. Further, most samples unblock clearly below $T_{\mathrm{g}}$ and alteration that is connected to unblocking above $T_{\mathrm{g}}$ (Smirnov and Tarduno, 2003) can be ruled out. Thus, it should be possible to determine a reliable paleointensity value using these samples, assuming that they carry a primary remanence. However, problems emerged due to heating of the samples: Heating above $T_{\mathrm{g}}$ of some samples and repeated heating to temperatures just below the glass transition introduced alteration into the experiments. Therefore, it was necessary to leave out data that was obtained above $T_{\mathrm{g}}$ and it was not possible to perform ATRM or CR correction on all samples. Nevertheless, the successful ATRM and CR experiments indicate negligible difference to uncorrected data. The uncorrected mean paleointensity of $57.0 \pm 1.0 \mu \mathrm{T}$ seems most reliable and can at least give an upper limit of the field strength $8 \mathrm{ka}$ ago in New Zealand, as faster cooling in the laboratory compared to nature leads to an overestimate of paleointensity when dealing with SD remanence carriers (Halgedahl et al., 1980; Dodson and McClelland-Brown, 1980). Interestingly, a comparison with previous intensity data from the same region shows excellent agreement: Within error our Mayor Island paleointensity data for $6050 \pm 70 \mathrm{BCE}$ is identical to the field value of $58.1 \pm 2.9 \mu \mathrm{T}$, which Tanaka et al. (2009) obtained for a $\sim 500$ year younger $(5500 \mathrm{BCE})$ rhyolithic lava at Okataina Volcanic Centre (OVC). OVC is a rhyolitic eruptive centre within Taupo Volcanic Zone and just $\sim 100 \mathrm{~km}$ distant from Mayor Island. Tanaka et al. (2009) did not apply any coolingrate correction. Normally one would expect different cooling rate dependencies. The match in the uncorrected data may be fortuitous, especially when considering the 500 year age difference. However, it might also indicate that in these cases the cooling rate does not have a strong influence. Nonetheless, it was tried to approximate a cooling rate corrected paleointensity value by comparison with other data. First the $f_{\text {CR }}$ of sample UOBS889 $(\sim 1.10)$ was used to correct our mean value of $57.0 \pm 1.0 \mu \mathrm{T}$. This gives a corrected value of $\sim 52 \mu \mathrm{T}$. This approach is justified due to the very similar magnetic properties of the different samples. However, as we have shown earlier (Leonhardt et al., 2006; Ferk at al., 2010), already slight variations in domain states result in changes in the TRM dependency on cooling rate. Thus, this value is only an approximation. Additionally, our uncorrected mean value was corrected by the $\sim 15 \%$ overestimate as observed for an obsidian with SD remanence carriers from Lipari (Leonhardt et al., 2006). Allthough these $15 \%$ come from another lava, they may be useful as they are a mean value for the whole flow. This yields a corrected value of $\sim 49 \mu \mathrm{T}$. Together these approximations suggest a cooling rate corrected paleointensity of $\sim 50 \mu \mathrm{T}$. Further studies will have to check whether the uncorrected or the corrected value is more likely. In their study on rhyolithic lava from OVC, Tanaka et al. (2009) have also compared their data to other volcanic and lake sediment data and to the geomagnetic field model CALS7K by Korte and Constable (2005). While the paleointensity data itself agrees well with a world-wide trend with a moderate high at 7-8 ka (Yang et al., 2000), there is a very poor fit to CALS7K. This is reasonable considering the paucity of reliable paleointensity data in the Pacific region to date and the thereby induced strong weighting of sedimentary data in the model. Further, geomagnetic field models are always less free to develop close to boundary due to the necessary boundary conditions. This may introduce additional errors at locations with few data. A comparison of our data with CALS7K is not possible as the model does not go back far enough. Therefore, agreement of the data with the so far unpublished geomagnetic field model by Leonhardt et al. (2010) that goes back to $10 \mathrm{ka}$ was tested. This model suggests a field value of only $\sim 43.5 \mu \mathrm{T}$ for $6050 \pm 70 \mathrm{BCE}$ at Mayor Island, which is closer to the cooling rate corrected value. However, due to the low number of data constraining the model, at this time it is impossible to say whether this is true, and more and better data are needed for the modelling procedures. Our new paleointensity value itself is of high quality. It is, therefore, an important first step towards a better global distribution of high quality data and betterdefined geomagnetic field models. Generally, obsidians may help to get a better data distribution as they are more evenly distributed about the globe than archeomagnetic data that so far are mainly used for the last thousands of years. This and other studies (Pick and Tauxe, 1993; Bowles et al., 2005; Leonhardt et al., 2006) suggest that volcanic glasses give very good paleomagnetic results and that they may, hence, help to obtain paleointensities and also directions for areas with no archeomagnetic data. 
Acknowledgements. We thank J. Bowles and A. Muxworthy for their thorough reviews that strongly helped to improve the manuscript. We are very thankful to J. Gottsmann for providing maps and data of his study (Gottsmann and Dingwell, 2002). Rock magnetic measurements at the Institute for Rock Magnetism were enabled by a Visiting Fellowship for A. Ferk. Our warmest thanks go to the whole IRM staff, especially to M. Jackson, for their help with the equipment and with interpretation of low temperature data. Further thanks to K. Fabian for help with Mathematica. Funding was provided by DFG grant Le1905/1-1 and FWF grant P21221-N14. D. B. Dingwell acknowledges the funding support of a LMUexcellent Research Professorship in experimental Volcanology (Bundesexzellenzinitiative) and ERC advanced grant EVOKES.

Edited by: F. Speranza

\section{References}

Bowles, J., Gee, J. S., Kent, D. V., Bergmanis, E., and Sinton, J.: Cooling rate effects on paleointensity estimates in submarine basaltic glass and implications for dating young flows, Geochem. Geophys. Geosys., 6, Q07002, doi:10.1029/2004GC000900, 2005.

Buck, M. D., Briggs, R. M., and Nelson, C. S.: Pyroclastic deposits and volcanic history of Mayor Island, N. Z. J. Geol. Geophys., 24, 449-4667, 1981.

Coe, R. S.: The determinations of paleointensities of the Earth's magnetic field with emphasis on mechanisms which could cause non-ideal behavior in Thellier's method, Geomag. Geoelec., 19, 157-179, 1967.

Coe, R. S., Grommé, S., and Mankinen, E. A.: Geomagnetic paleointensities from radiocarbon-dated lava flows on Hawaii and the question of the Pacific nondipole low, J. Geophys. Res., 83, 1740-1756, 1978.

Cottrell, R. D. and Tarduno, J. A.: Geomagnetic paleointensity derived from single plagioclase crystals, Earth Planet. Sci. Lett., 169, 1-5, 1999.

Day, R., Fuller, M. D., and Schmidt, V. A.: Hysteresis properties of titanomagnetites: Grain size and composition dependence, Phys. Earth Planet. Inter., 13, 260-266, 1977.

Dekkers, M. J. and Böhnel, H. N.: Reliable absolute palaeointensities independent of magnetic domain state, Earth Planet. Sci. Lett., 248, 508-517, 2006.

Dingwell, D. B. and Webb, S. L.: Relaxation in silicate melts, Eur. J. Mineral., 2, 427-449, 1990.

Dodson, M. H. and McClelland-Brown, E.: Magnetic blocking temperatures of single-domain grains during slow cooling, J. Geophys. Res., 85, 2625-2637, 1980.

Fabian, K. and Leonhardt, R.: Multiple-specimen absolute paleointensity determination: An optimal protocol including pTRM normalization, domain-state correction, and alteration test, Earth Planet. Sci. Lett., 297, 84-94, 2010.

Ferk, A., v. Aulock, F. W., Leonhardt, R., Hess, K.-U., and Dingwell, D. B.: A cooling rate bias in paleointensity determination from volcanic glass: an experimental demonstration, J. Geophys. Res., 115, B08102, 1-8, doi:10.1029/2009JB006964, 2010.
Fox, J. M. W. and Aitken, M. J.: Cooling-rate dependency of thermoremanent magnetisation, Nature, 283, 462-463, 1980.

Genevey, A., Gallet, Y., Constable, C. G., Korte, M., and Hulot, G.: ArcheoInt: An upgraded compilation of geomagnetic field intensity data for the past ten millennia and its application to the recovery of the past dipole moment, Geochem. Geophys. Geosys., 9, Q04038, doi:10.1029/2007GC001881, 2008.

Gottsmann, J. and Dingwell, D. B.: The cooling of frontal flow ramps: a calorimetric study on the Rocche Rosse rhyolite flow, Lipari, Aeolian Islands, Italy, Terra Nova, 19, 157-164, 2001.

Gottsmann, J. and Dingwell, D. B.: The thermal history of a spatterfed lava flow: the 8-ka pantellerite flow of Mayor Island, New Zealand, Bull. Volcanol., 64, 410-422, 2002.

Halgedahl, S. L., Day, R., and Fuller, M.: The effect of cooling rate on the intensity of weak-field TRM in single-domain magnetite, J. Geophys. Res., 85, 3690-3698, 1980.

Houghton, B. F. and Wilson, C. J. N.: Explosive rhyolitic volcanism: the case studies of Mayor Island and Taupo Volcanoes, N. Z. Geol. Surv. Records, 12, 33-100, 1986.

Houghton, B. F., Weaver, S. D., Wilson, C. J. N., and Lanphere, M. A.: Evolution of a Quaternary peralkaline volcano; Mayor Island, New Zealand, J. Vol. Geoth. Res., 51, 217-236, 1992.

Korte, M. and Constable, C. G.: Continuous geomagnetic field models for the past 7 millennia: 2. CALS7K, Geochem. Geophys. Geosys., 6, Q02H16, doi:10.1029/2004GC000801, 2005.

Krása, D., Heunemann, C., Leonhardt, R., and Petersen, N.: Experimental procedure to detect multidomain remanence during Thellier-Thellier experiments, Phys. Chem. Earth, 28, 681-687, 2003.

Leonhardt, R.: Analyzing rock magnetic measurements: The RockMagAnalyzer 1.0 software, Computers \& Geosciences, 32, 1420-1431, 2006.

Leonhardt, R., Krása, D., and Coe, R. S.: Multidomain behavior during Thellier paleointensity experiments: A phenomenological model, Phys. Earth Planet. Inter., 147, 127-140, 2004 a.

Leonhardt, R., Heunemann, C., and Krása, D.: Analyzing absolute paleointensity determinations: Acceptance criteria and the software ThellierTool4.0, Geochem. Geophys. Geosys., 5, Q12016, doi:10.1029/2004GC000807, 2004b.

Leonhardt, R., Matzka, J., Nichols, A. R. L., and Dingwell, D. B.: Cooling rate correction of paleointensity determination for volcanic glasses by relaxation geospeedometry, Earth Planet. Sci. Lett., 243, 282-292, 2006.

Leonhardt, R., Fabian, K., and Schnepp, E.: Holocene global geomagnetic field reconstruction based on archeomagnetic data: Assessing error sources and uncertainties, EGU General Assembly, Vienna, Austria, 2-7 May 2010, EGU2010-9421, 2010.

Macdonald's, R. A.: Nomenclature and petrochemistry of the peralkaline oversaturated extrusive rocks, Bull. Volcanol., 38, 498516, 1974.

McClelland-Brown, E.: Experiments on TRM intensity dependence on cooling rate, Geophys. Res. Lett., 11, 205-208, 1984.

Moskowitz, B. M., Jackson, M., and Kissel, C.: Low-temperature magnetic behavior of titanomagnetites, Earth Planet. Sci. Lett., 157, 141-149, 1998.

Muxworthy, A. R. and Heslop, D.: A Preisach method for estimating absolute paleofield intensity under the constraint of using only isothermal measurements: 1 . Theoretical framework, J. Geophys. Res., 116, B04102, doi:10.1029/2010JB007843, 2011. 
Papusoi, C.: Effet de la vitesse de refroidissement sur l'intensité de l'aimantation thermorémanente d'un ensemble de grains monodomaines, An. Stiint. Univ. "Al.I. Cuza" Iasi Sect. Ib Tomul, 18, 31-47, 1972.

Pick, T. and Tauxe, L.: Geomagnetic paleointensities: Thellier experiments on submarine basaltic glass from the East Pacific Rise, J. Geophys. Res., 98, 17949-17964, 1993.

Riisager, P. and Riisager, J.: Detecting multidomain magnetic grains in Thellier paleointensity experiments, Phys. Earth Planet. Inter., 125, 111-117, 2001.

Selkin, P. A. and Tauxe, L.: Long-term variations in paleointensity, Phil. Trans. R. Soc., 358, 1065-1088, 2000.

Smirnov, A. V. and Tarduno, J. A.: Magnetic hysteresis monitoring of Cretaceous submarine basaltic glass during Thellier paleointensity experiments: evidence for alteration and attendant low field bias, Earth Planet. Sci. Lett., 206, 571-585, 2003.

Stevenson, R. J., Briggs, R. M., and Hodder, A. P. W.: Emplacement history of a low viscosity, fountain-fed pantelleritic lava flow, J. Vol. Geoth. Res., 57, 39-56, 1993.

Tanaka, H., Komuro, N., and Turner, G. M.: Palaeosecular variation for 0.1-21 Ka from the Okataina Volcanic Centre, New Zealand, Earth Planets Space, 61, 213-225, 2009.
Tarduno, J. A., Cottrell, R. D., Watkeys, M. K., and Bauch, D.: Geomagnetic field strength 3.2 billion years ago recorded by single silicate crystals, Nature, 446, 657-660, 2007.

Tool, A. Q.: Relation between inelastic deformability and thermal expansion of glass in its annealing range, J. Am. Ceram. Soc., 29, 240-253, 1946.

Valet, J.-P., Brassart, J., Le Meur, I., Soler, V., Quidelleur, X., Tric, E. and Gillot, P.-Y.: Absolute paleointensity and magnetomineralogical changes, J. Geophys. Res., 101, B11, 25029-25044, 1996.

Veitch, R. J., Hedley, I. G., and Wagner, J.-J.: An investigation of the intensity of the geomagnetic field during Roman times using magnetically anisotropic bricks and tiles, Arch. Sc. Genéve, 37, 359-373, 1984.

Wilding, M. C., Webb, S. L., and Dingwell, D. B.: Evaluation of a relaxation geospeedometer for volcanic glasses, Chem. Geol., 125, 137-148, 1995.

Yang, S., Odah, H., and Shaw, J.: Variations in the geomagnetic dipole moment over the last 12000 years, Geophys. J. Int., 140, 158-162, 2000. 